\title{
Illustration
}

\section{Fournier's Gangrene in a Diabetic Young Man}

\section{Soufiane Ennaciri, MD*; Mustapha Ahsaini, PhD; Moulay Hassan Farih, PhD}

Department of Urology, Hassan II University Hospital, Fes, Morocco

\section{"Corresponding author}

Soufiane Ennaciri, MD

Department of Urology, Hassan II University Hospital, Fes, Morocco; E-mail: soufenna@hotmail.com

\section{Article Information}

Received: February 18 ${ }^{\text {th }}$, 2019; Accepted: March 7 $7^{\text {th }}$ 2019; Published: March 14 ${ }^{\text {th }}, 2019$

\section{Cite this article}

Ennaciri S, Ahsaini M, Farih MH. Fournier's gangrene in a diabetic young man. Urol Androl Open J. 20I9; 3(I): 6. doi: I0.17I40/UAOJ-3-II7

Q necrotizing fasciitis that affects the genital, perineal, or perianal regions of the body. It is usually secondary to perirectal or periurethral infections associated with local trauma, operative procedures, or urinary tract disease.

We report the case of a 49-years-old man with uncontrolled type 2 diabetes, presented to the emergency department with painful swelling in the scrotum and perianal region. His temperature was $38.8^{\circ} \mathrm{C}$, his pulse 120 beats per minute, and his blood pressure $98 / 60 \mathrm{mmHg}$. The physical examination revealed necrosis in the external genitalia and erythema in the hypogastric region and perineum with induration and crepitus (Figure 1A). Computed tomography revealed a scrotal collection with subcutaneous emphysema in the lower abdomen, scrotum and perianal fascia. A diagnosis of Fournier's gangrene was made.
The treatment consisted of a necrosectomy and drainage of collections with achieving discharge incisions in the perineum and lower abdomen. In addition to surgery, the patient received volume replacement and broad-spectrum intravenous antibiotics.

The evolution was favorable after several days of care (Figure 1B). After that the patient was entrusted to reconstruction surgery.

\section{CONSENT}

The authors have received written informed consent from the patient.

\section{CONFLICTS OF INTEREST}

The authors declare that they have no conflicts of interest.

Figure I. A. Pre-Operative Photo Showing External Genitalianecrosis and Hypogastric Erythema. B. Post-Operative Photo After Excision of the Necrotic Tissue and Discharge Incisions

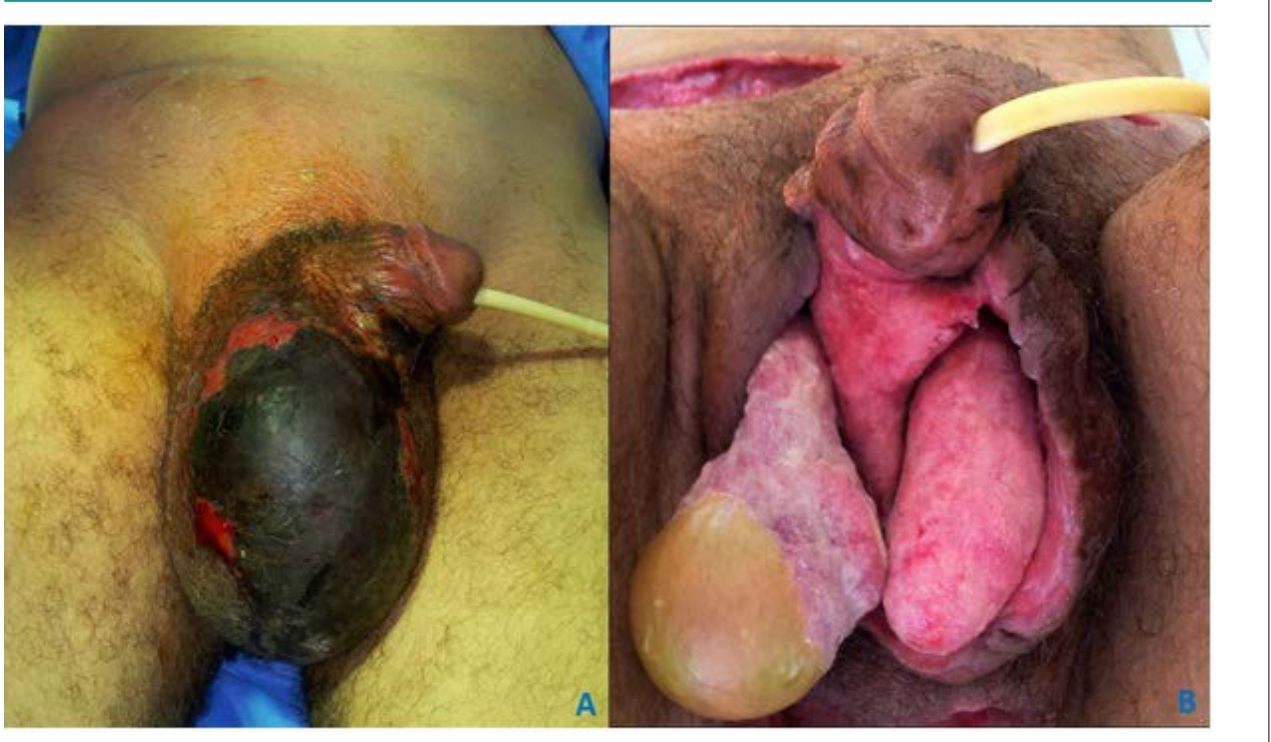

(a) Copyright 2019 by Ennaciri S. This is an open-access article distributed under Creative Commons Attribution 4.0 International License (CC BY 4.0), which allows to copy, redistribute, remix, transform, and reproduce in any medium or format, even commercially, provided the original work is properly cited. 